\title{
Multi-scale phase analyses of strain-induced martensite in austempered ductile iron (ADI) using neutron diffraction and transmission techniques
}

\author{
Xiaohu $\mathrm{Li}^{1, \star} \mathbb{0}$, Sergio Soria ${ }^{2}$, Weimin Gan ${ }^{1}$, Michael Hofmann², Michael Schulz ${ }^{2}$, \\ Markus Hoelzel $^{2}$, Heinz-Günter Brokmeier ${ }^{3}$, and Winfried Petry ${ }^{2}$ \\ ${ }^{1}$ German Engineering Materials Science Centre (GEMS) At Heinz Maier-Leibnitz Zentrum (MLZ), Helmholtz-Zentrum Geesthacht \\ GmbH, Lichtenbergstr. 1, 85748 Garching, Germany \\ ${ }^{2}$ Heinz Maier-Leibnitz Zentrum (MLZ), Technische Universität München, Lichtenbergstr. 1, 85747 Garching, Germany \\ ${ }^{3}$ Institute of Materials Science and Engineering, TU Clausthal, 38678 Clausthal-Zellerfeld, Germany
}

Received: 24 August 2020

Accepted: 24 November 2020

Published online:

10 December 2020

(C) The Author(s) 2020

\begin{abstract}
The content of strain-induced martensite in austempered ductile iron has been quantitatively determined using three different kinds of neutron methods: (1) high-resolution powder diffraction with subsequent standard Rietveld refinement, (2) phase quantification using pole figure measurements and (3) Bragg edge neutron transmission. The accuracy and scope of applications of these neutron diffraction and imaging techniques for phase quantification have been compared and discussed in detail. Combination of these methods has been confirmed as effective for dealing with problems like peak overlap in multiphase materials and texture formation after plastic deformation. Further, the results highlight the potential of using single peak pole figure data for quantitative phase analysis with high accuracy.
\end{abstract}

\section{Introduction}

Austenite, ferrite and martensite are the most prominent phases in iron-based materials. Many different kinds of methods like diffraction (XRD, synchrotron/neutron diffraction), Bragg edge transmission (BET), magnetic balance measurements, image analysis (optical microscopy, EBSD) have been used for quantification of phase contents in iron- based materials over the last decades [1-5]. Image analysis depends crucially on the quality of sample preparation; it can provide fast phase quantification with accuracy of \pm 2 vol. \% only when the parameters of the whole sample preparation process are optimized [1]. However, its application is severely limited by the grain size of the material, as samples with a grain size of less than $250 \mathrm{~nm}$ are not accessible $[6,7]$. The magnetic balance method requires the existence of a single magnetic phase in multi-phase

Handling Editor: P. Nash.

Address correspondence to E-mail: xiaohu.li@hzg.de 
alloys for quantitative phase analysis. The theoretical magnetic saturation of a sample with known phase composition will be calculated using an empirical equation [1,8] and is subsequently taken as reference sample [1]. Imperfections in magnetic field, inaccuracy in sample weight and variation in spring modulus of elasticity result in relatively large errors in the calculation. If powder reference samples are used for calibration, an accuracy of \pm 4 vol. $\%$ in the phase quantification can be achieved [1,5]. However, using this method in a bulk material without prior calibration with powder reference samples can cause errors of $20 \mathrm{vol} . \%$ or more in the results of a phase content analysis [5]. Compared to these two methods, powder diffraction plus standard Rietveld analysis has been widely used in various classes of materials over many years, and its accuracy for quantitative phase analysis has been thoroughly tested in numerous round robin campaigns [9-13]. Furthermore, also lattice parameters of phases, grain size and strain/stress information can additionally be derived in course of the data analysis of the diffraction pattern. Therefore, results obtained through quantitative phase analysis using diffraction methods are regarded to be reliable and might be considered as a benchmark in scientific investigations. Even so, phase quantification using diffraction methods is far from being a routine task and suffers inadequacies due to some characteristics of the specimen itself. The Rietveld analysis on multi-phase steels can be challenging due to texture effects on the peak intensities, possible peak shifts due to residual stress and severe line broadening from plastic deformation. For example, in the case of austempered ductile iron (ADI), the austenite phase in ADI is meta-stable under plastic deformation and will transform into martensite. As a result, the austenite content in the compressed ADI samples is lower than in the undeformed initial reference sample. However, for this type of analysis dedicated software packages are essential. For example the software package MAUD [14] can deal with complicated microstructures, in particular the complete orientation distribution function (ODF) can be implemented into the Rietveld analysis.

In the following two neutron diffraction-based techniques, Bragg edge neutron transmission and texture analysis using pole figure data are described to deal with problems caused by peak overlap and formation of preferred orientation of grains. Both methods show promising results in the case of quantification of the strain-induced martensite in austempered ductile iron (ADI), and it is anticipated that they will become powerful tools for phase quantification in general.

Bragg edge neutron transmission was first proposed in 1988 by Priesmeyer [15] and Bowman et al. [16] and then successfully applied in gray iron for quantitative phase analysis [17]. In the current article, the neutron transmission has been used to quantify the martensite content in ADI without consideration of texture effects. It was successfully applied in mildly textured austenitic stainless steel before; but the accuracy of using this method in phase quantification has not been examined in detail yet [18]. The results in the current paper are to address this issue.

Quantitative phase analysis using the results of pole figure/ODF was first reported for textured Al$\mathrm{Cu}$ alloys and graphite [19]. However, after that, the method has not been widely spread to phase quantification in textured materials. The main reason is that in order to avoid the error caused by the inhomogeneously distributed texture formation, and it is necessary to measure the texture distribution of the entire sample, so the measurement can only be completed by using neutron diffraction as only here a large gauge volume can be achieved. The lack of corresponding experiments has the consequence that the accuracy of this method for phase quantification for different materials and its measurement conditions still needs to be developed. In case of deformed ADI material, we have already shown that using standard Rietveld analysis considering the texture can yield phase contents with very high accuracy (error in phase volume fraction is less than 2 vol. \%) [20]. However, the experimental effort and data analysis processes are quite time consuming and we therefore aim to a practical approach of this method making it more time efficient and simplifying the whole process.

\section{Experimental and methods}

\section{Sample preparation}

The initial cast ductile iron plates, produced by Bosch Rexroth AG with the dimension of $140 \times 110 \times 20 \mathrm{~mm}^{3}$, were machined to a cylindrical shape with a diameter of $6 \mathrm{~mm}$ and a length of 
$10 \mathrm{~mm}$. The chemical composition of the samples is listed in Table 1 (see also [20]).

The cylindrical samples were subjected to a twostage heat treatment in a mirror furnace with inert Ar gas atmosphere. All samples have been austenitized at $900{ }^{\circ} \mathrm{C}$ for $30 \mathrm{~min}$. After austenitization, ten samples with $0 \mathrm{wt} \% \mathrm{Ni}$ were quenched to $350{ }^{\circ} \mathrm{C}$ and austempered for $30 \mathrm{~min}$, while another set of samples with $1.5 \mathrm{wt} \% \mathrm{Ni}$ were also quenched to $350{ }^{\circ} \mathrm{C}$, but a holding time of $35 \mathrm{~min}$ was needed to reach carbon content saturation in that case [21]. Finally, all the samples have been cooled to room temperature after austempering.

The samples were then compressed ex situ using a test rig [22] at a strain rate of $4 \times 10^{-4} \mathrm{~s}^{-1}$ to different strain levels. Details on the compressive deformation process are found in [20].

\section{Phase content quantification using the Rietveld method}

Neutron diffraction patterns of compressed ADI samples with $0 \mathrm{wt} \%$ and $1.5 \mathrm{wt} \% \mathrm{Ni}$ were collected using the SPODI diffractometer [23] at FRM II/MLZ over a $2 \Theta$ range $=10 \sim 152 \mathrm{deg}$. Details on the instrument settings of the measurements have already been published in [20] and can be found there. Using the software package MAUD [14], the neutron diffraction pattern and calculated orientation distribution functions (ODFs) from the measured pole figures have been combined for further quantitative phase analysis.

\section{Phase quantification using texture data analysis}

Complete pole figures of ferrite (200) of ADI samples $\left(0 \mathrm{wt} \% \mathrm{Ni}\right.$, austempered at $350{ }^{\circ} \mathrm{C}$ ) which have been compressed to $0 \%, 10 \%, 20 \%, 30 \%$ and $40 \%$ strain levels were measured at the materials science diffractometer STRESS-SPEC at MLZ [24] with a wavelength of $1.68 \AA$ using a Ge (311) monochromator. Being an isolated non-overlapping peak in the diffraction pattern, the intensity of the austenite (200) reflection can be used as a scaling value for its corresponding austenite content. The integrated intensity of the austenite (200) peak in the complete pole figure has therefore been used for austenite phase fraction determination, which was then further used to calculate the respective martensite content.

\section{Phase quantification using Bragg edge neutron transmission (BET)}

The neutron radiography experiment was carried out at the cold neutron radiography and tomography facility (ANTARES) at MLZ $[25,26]$. ANTARES is fed by a continuous beam of cold neutrons. In the radiographic measurement, five compressed ADI samples with $1.5 \mathrm{wt} \% \mathrm{Ni}$ were stacked together in the vertical direction and put into the neutron beam (beam size $\sim 80 \mathrm{~mm} \times 80 \mathrm{~mm}$ (Fig. 1a)). A cooled scientific CMOS camera with $2560 \times 2160$ pixels in combination with a $100 \mu \mathrm{m}$ thick LiF:ZnS scintillator was used as detector system. To get more quantitative information about martensite, a large wavelength range between 1.6 and $5.9 \AA$ was scanned by means of the double crystal option of ANTARES with a wavelength resolution step of $0.05 \AA$ [27].

In the second measurement, each of the five samples has been placed with its cylindrical axis parallel to the neutron beam (Fig. 1b). Both beam directions in Fig. 1a and $b$ can be used for the measurement of transmission spectra. For the second measurement with two wavelengths, the geometric effects (texture and barreling effect of the sample) can be effectively avoided using the cylindrical symmetry of the sample in the beam setup shown in Fig. 1b. This way spatially resolved information about the phase distribution over the sample cross section can be obtained without performing a time consuming tomography. Two monochromatic wavelengths $3.9 \AA$ and $4.5 \AA$ were chosen for this measurement. The attenuation coefficients at these two wavelengths of the individual samples were collected simultaneously for further calculation.

Table 1 Chemical composition of cast ductile iron material used for compressive deformation

\begin{tabular}{lllllll}
\hline & $\mathrm{C}$ & $\mathrm{Si}$ & $\mathrm{Mn}$ & $\mathrm{Ni}$ & $\mathrm{Cu}, \mathrm{Mo}, \mathrm{P}, \mathrm{S}$ & $\mathrm{Fe}$ \\
\hline Elementary chemical composition in wt $\%$ & $3.6 \sim 3.7$ & 2.3 & 0.2 & 0 or 1.5 & less than 0.08 & balance \\
\hline
\end{tabular}


(a)

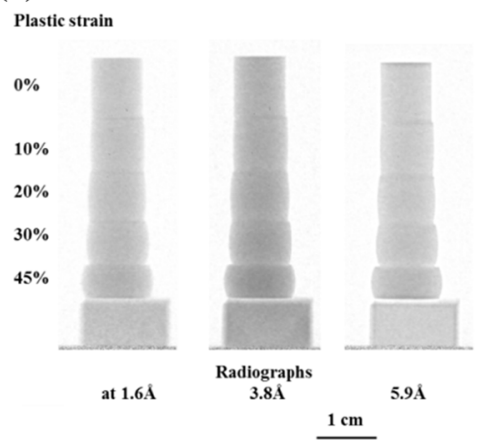

(b)

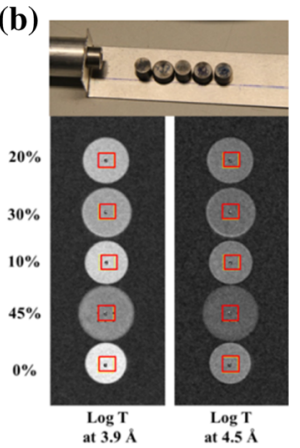

Figure 1 a Example images of the first measurement for Bragg edge height calculation. Neutron radiographs in the Bragg edge transmission (BET) measurement at different wavelengths. In this measurement, the samples were superimposed in the vertical direction. $\mathbf{b}$ Example images of the second measurement using two wavelengths. Geometry of ADI samples and its corresponding neutron radiograph. In this measurement, the samples were mounted with the base on a thin Al plate, and the incoming beam direction is perpendicular to the plane surface.

\section{Results and discussion}

\section{Rietveld refinement with consideration of texture}

As mentioned in the introduction, the results obtained using Rietveld method is set as benchmark in the comparison of the BET/Rietveld and Texture/ Rietveld methods.

Figure 2 shows the results obtained from the Rietveld method with consideration on texture formation. These results have already been published in our previous research work [20]. The following discussion about different neutron techniques in phase quantification is based on them, and we highlight the differences between BET/Rietveld and Texture/Rietveld methods.

\section{Bragg edge transmission analysis}

Quantitative phase analysis by BET has been carried out using two methods: first, analyzing the height of the Bragg edges in the BET spectrum and second, calculating the attenuation ratio of neutron images acquired at two different wavelengths. Both approaches will be discussed in the following paragraphs.

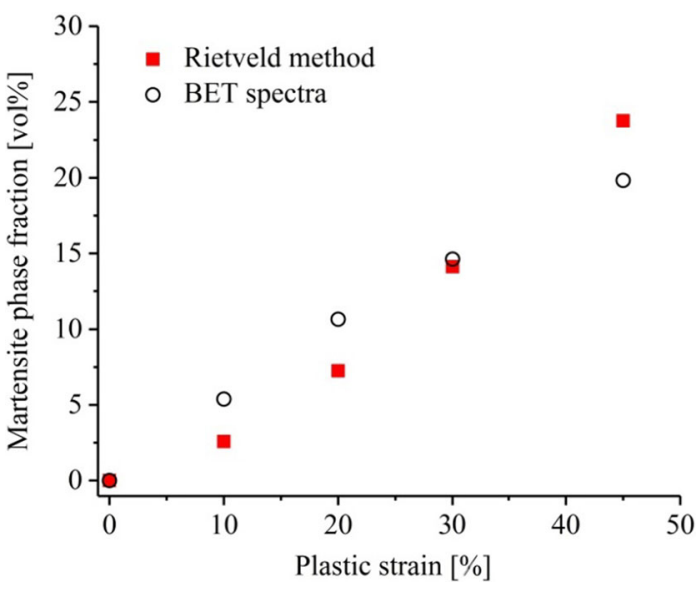

Figure 2 Martensite phase fraction vs. plastic strain in ADI with $0 \mathrm{wt} \%$ and $1.5 \mathrm{wt} \% \mathrm{Ni}$, austempered at $350{ }^{\circ} \mathrm{C}$ as determined by Rietveld refinement of the high-resolution neutron powder diffraction data [20]. Error bars are within the size of the symbols.

\section{First method: Bragg edge height calculation}

The theoretical background of using Bragg edge height for quantitative phase analysis is based on the Kroppf model (Eq. (1)) [28]. Figure 3a shows the theoretical transmission spectra of $100 \%$ austenitic and $100 \%$ ferritic Fe calculated using the software Nxs [29]. Thus, the ferrite (110) and austenite (111) edges nearby $\lambda=4.0 \AA$ cannot be resolved and separated due to the limited wavelength resolution at the reactor-based sources. Still it would be the best choice for martensite quantification as the attenuation coefficient differences of ferrite at other edges (e.g., ferrite (200) or (211)) are small and less suitable for quantitative phase analysis (Fig. 3a). Here, the Bragg edge height of ferrite (110) was chosen to be calculated for all the $b c c$ phase fraction contents in ADI. The measured Bragg Edge of undeformed ADI is shown in Fig. 3b. Examples using this method with practical experiment performance and data analysis process have been introduced in $[30,31]$ in details. The Bragg edge height of the ferrite (110) reflection in ADI samples with different strain levels has been calculated using the Kroppf model [28] and compared with martensite content calculated using the standard Rietveld method (Fig. 3c). Because of the proportionality between Bragg edge height (110) reflex and $b c c$ phase content, a linear fit between them was performed to quantify their relationship (Fig. 3c). The ADI sample with $0 \%$ strain (bcc phase: 60 vol. $\%$ ferrite and 0 vol. $\%$ martensite, $f c c$ phase: $40 \%$ austenite) was set as reference/start point in the 

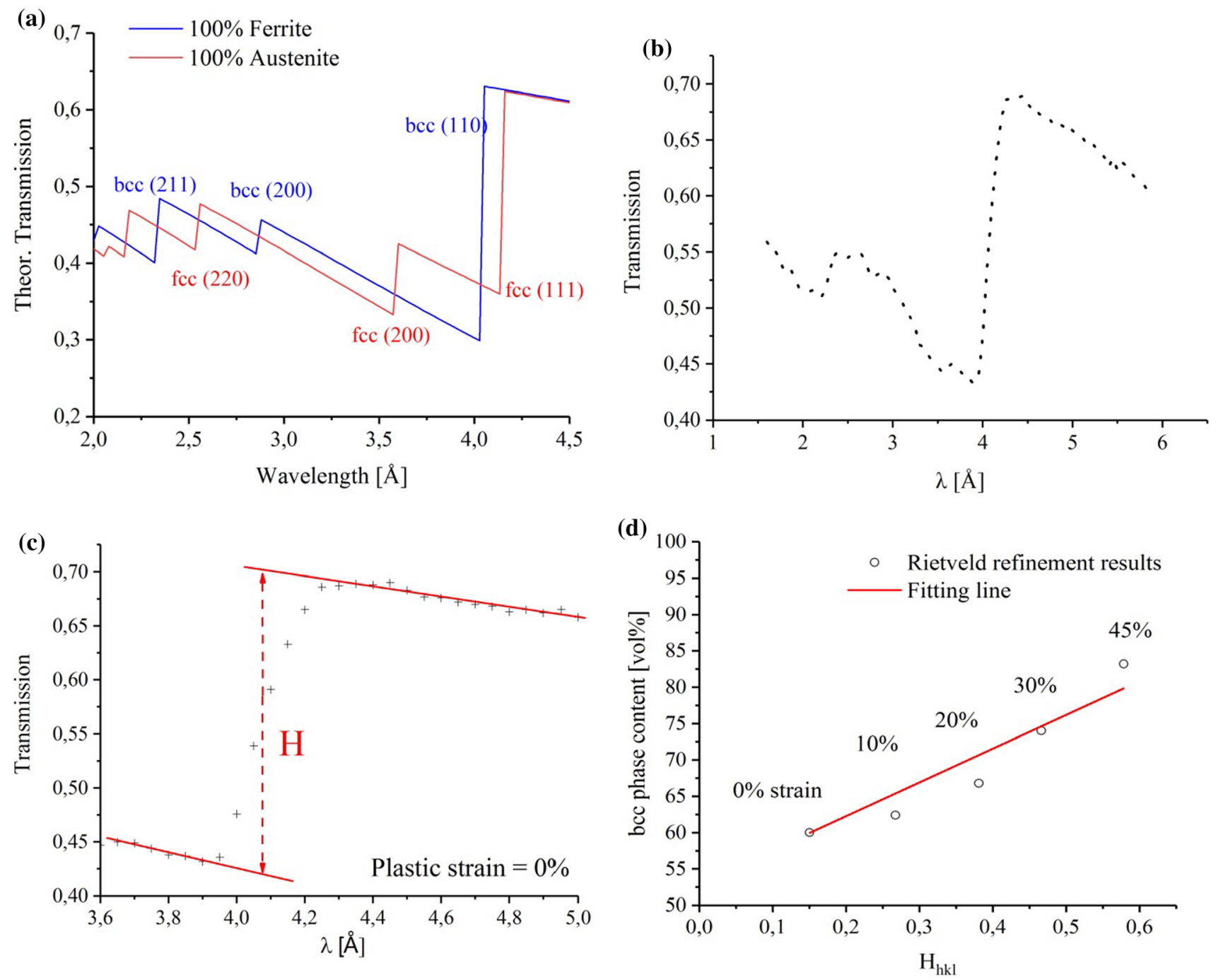

Figure 3 a Theoretical transmission spectra of $100 \%$ fcc austenite and alternatively $100 \%$ bcc ferrite/martensite calculated using Nxs program [29]. b Measured transmission spectra of the ADI sample with $0 \%$ strain. c Enlarged view of Fig. $3 \mathrm{~b}$ in the wavelength

fitting line, and the martensite contents calculated using this fitting line have been set in Fig. 4 to compare with the results obtained by the Rietveld method.

$H_{\mathrm{hkl}}=\sigma_{\mathrm{NB}}(\lambda)+\sigma_{\mathrm{hkl}}(\lambda)=a_{\mathrm{hkl}}+b_{\mathrm{hkl}} \lambda_{\mathrm{hkl}}$

$H_{\mathrm{hkl}}$ : Bragg edge height of $h k l$ reflection, $\sigma_{\mathrm{NB}}(\lambda)$ : fitting function on the right side of the Bragg edge, $\sigma_{\mathrm{hkl}}$ $(\lambda)$ : fitting function on the left side of the Bragg edge, $a_{\mathrm{hkl}}, b_{\mathrm{hkl}}$ : constant in the Gaussian function determined from the relationship between $\sigma_{\mathrm{NB}}(\lambda)$ and $\sigma_{\mathrm{hkl}}$ ( $\lambda$ ) for a $\lambda=\lambda_{\mathrm{hkl}}$ and $\lambda$ : neutron wavelength change from $1.6 \AA$ to $5.9 \AA$ with a wavelength resolution step of $0.05 \AA$.

ranging from 3.6 to $5.0 \AA$. d Bragg edge height $\mathrm{H}$ vs. bcc ferrite/martensite content in ADI as determined by Rietveld analysis of diffraction data. The straight line represents to a linear fit gauging attenuation ratio versus $\mathrm{H}$.

The difference between the values determined by $B E T$ and the reference values reflects the accuracy of the BET method in phase quantification. Figure 4 shows the differences in martensite content measured and calculated by these two methods, ranging from 0.5 to 3.9 vol. \%. These differences are within an acceptable range as compared to the martensite content measured by other methods [32, 33]. Further analysis shows that two main reasons are responsible for the observed differences in phase content obtained by these two methods. First, the wavelength increment (resolution) of our neutron radiograph is $0.05 \AA$ making it difficult to separate the Bragg edges of ferrite (110) and austenite (111). A remedy here 


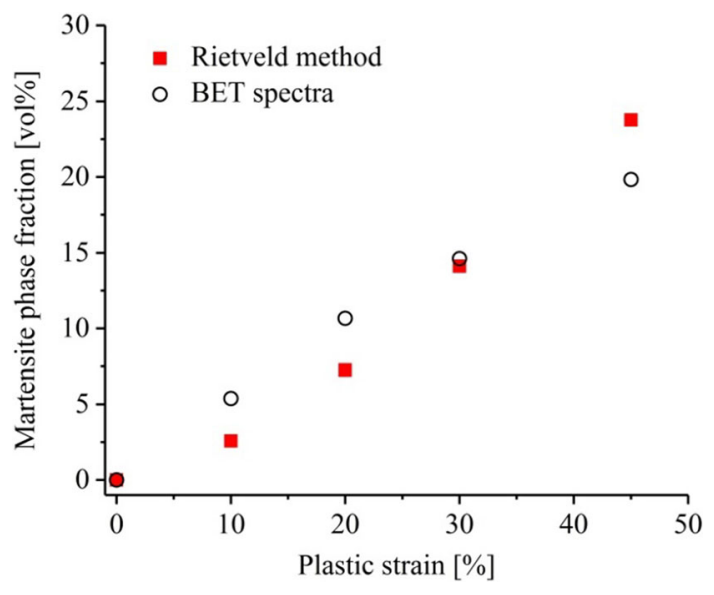

Figure 4 Comparison of Rietveld method and BET spectra analysis in martensite phase quantification. The ADI samples with $1.5 \mathrm{wt} \% \mathrm{Ni}$ content and austempered at $350{ }^{\circ} \mathrm{C}$ were compressed to different strain levels between 0 and $45 \%$.

would be to use a time-of-flight source with inherently better wavelength resolution which therefore can separate these two Bragg edges and most likely enhance the accuracy of neutron transmission in phase quantification [34]. Second, the existence of texture in ADI after plastic deformation has not been considered in the analysis of the BET measurements, which might have also influenced the accuracy of phase content quantification [35].

\section{Second method: attenuation ratio of two wavelengths}

The above-mentioned evaluation method relies on the height of the Bragg edge. Any feature, which depends on the neutron energy below the wavelength resolution limit, will be lost in this averaging process. This drawback can be overcome directly comparing the height of the image contrast on both sides of a Bragg edge (for example in Fig. 3a, at the $b c c$ (110) Bragg edge). The attenuation ratio relates directly to the phase fraction ration of $b c c$ and $f c c$ phases in the sample. Its basic theoretical background and detailed examples are explained in [34, 36]. Based on this, Eq. (2) [36] is derived for the attenuation ratio calculation. Now two wavelengths $(3.9 \AA$ and $4.5 \AA$ ) on both sides of the (110) ferrite Bragg edge $(4.1 \AA$ ) were chosen for radiography measurements, and the attenuation ratio of these two measurements has been used for further martensite phase analysis. $\frac{\log I_{\lambda_{2}}}{\log I_{\lambda_{1}}}=\frac{\mu \sigma_{\lambda_{2}} d}{\mu \sigma_{\lambda_{1}} d}$

$I_{\lambda_{1}, \lambda_{2}}$ : Intensity at wavelength $3.9 \AA$ and $4.5 \AA, \mu$ : number density of neutron interaction centers, $\sigma_{\lambda_{1}, \lambda_{2}}$ : neutron total cross section at $3.9 \AA$ and $4.5 \AA$ and $d$ : thickness of sample.

The areas marked with red squares in Fig. $1 \mathrm{~b}$ were used for attenuation ratio calculation. The determined attenuation ratios of different compressed ADI samples have been plotted together with the phase analysis results obtained using the standard Rietveld refinement in Fig. 5.

The $b c c$ phase contents (ferrite + martensite) calculated using the Rietveld method were plotted as a function of attenuation ratio measured by BET and fitted using a linear equation (Fig. 5). Similar to the first method, the ADI sample without plastic deformation which contains 60 vol. \% ferrite and 0 vol. \% martensite was set as the reference/start point in the fitting line. The attenuation ratios calculated using BET are linearly related to the martensite content [35]. From Fig. 5, the martensite contents can be directly calculated and direct comparison between the results obtained by Rietveld method and BET using two wavelengths is shown in Fig. 6 as a function of deformation level. Differences between the direct Rietveld analysis and that based on attenuation ratios are at maximum 2.3 vol. \%. Thus, the martensite

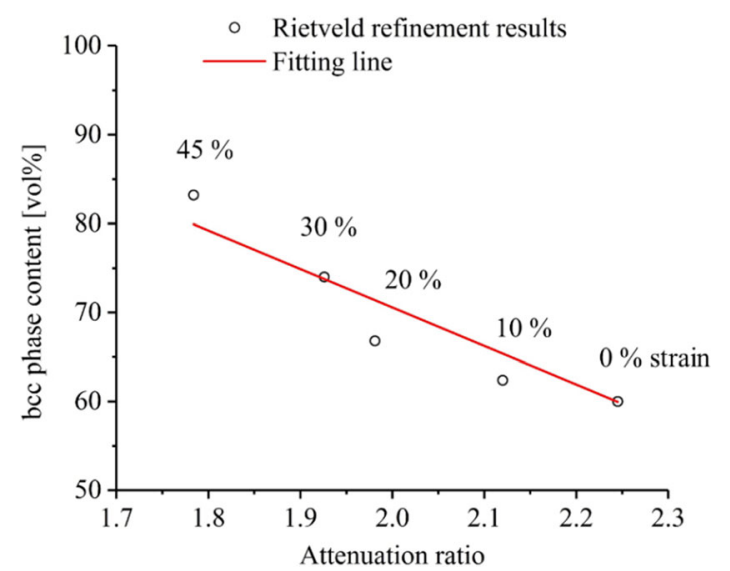

Figure 5 Attenuation ratio of the two wavelengths $3.9 \AA$ and $4.5 \AA$. vs. martensite content as determined by Rietveld analysis of diffraction data. The open symbols are the results from the Rietveld refinements of differently deformed ADI samples (the numbers above the symbols give the degree of deformation). The straight line represents to a linear fit gauging attenuation ratio versus $b c c$-martensite content. 
contents obtained using the second method are close to the results obtained from the first method. This indicates that the second method using BET is also an effective method for martensite phase quantification with, the added advantage of distinctly shorter experiment times.

The main reason for the difference between the results obtained by BET method and Rietveld method is the inhomogeneous distribution of martensite during plastic deformation [35]. As shown in Fig. 1, the data collection area of the BET method is focused in the middle of the sample, while the data used in the Rietveld method come from the whole sample. In our previous results [35], we have confirmed that the deformation level in the middle part of the sample is higher than in the other areas at the beginning of the plastic deformation (strain $<20 \%$ ). In the later stage of plastic deformation (strain $>30 \%$ ) the situation becomes the opposite.

\section{Phase analysis using pole figure data}

Quantitative phase analysis using diffraction is based on the fact that the total scattering intensity of any phase is directly proportional to its phase volume fraction. Here, each individual Bragg reflection in a diffraction pattern represents only a specific proportion of the scattered neutrons [37] where the relationship of phase volume fraction and scattered intensity of this reflection $(h k l)$ can be expressed through Eq. (3). This relationship is the fundamental principle of quantitative phase analysis using texture

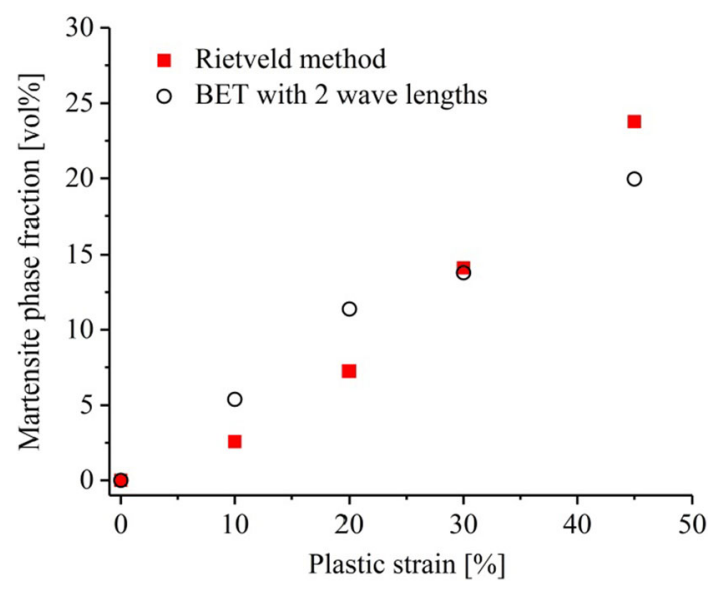

Figure 6 Comparison of Rietveld method and BET imaging with two different wavelengths in martensite phase quantification. The ADI samples with $1.5 \mathrm{wt} \% \mathrm{Ni}$ content and austempered at $350{ }^{\circ} \mathrm{C}$ were compressed to different strain levels between 0 and $45 \%$. data, i.e., in austenite, the relationship in Eq. (3) applies to the total scattering intensity of any Bragg reflection $(h k l)$ of the austenite in ADI [37]. The constant $K$ in Eq. (3) is between 0.98 and 1 for all our samples. This factor is related to the effects which may influence the total intensity in the diffraction patterns, like mosaicity change of crystals caused by strain-induced martensitic transformation, fluctuation of neutron flux etc.

$I_{\gamma, \mathrm{hkl}}=V_{\gamma} \mathrm{KR}_{\gamma, \mathrm{hkl}} A_{m}$

$I_{\gamma, \mathrm{hkl}}$ : integrated intensity of reflection $(h k l)$ for austenite, $V_{\gamma}$ : volume fraction of austenite, $K$ : constant specific of the experiment [21,37], $R_{\gamma, \mathrm{hkl}}$ : scattering factor of reflection $(h k l)$ for austenite [37] and $A_{m}$ : absorption factor of the phase mixture. In the case of ADI, both ferrite and austenite are iron phase, so the absorption factor of both phases is the same [38].

Furthermore, the total integrated intensity of a bulk material in a pole figure is theoretically equal to the scattering intensity measured from its powder sample equivalent, which effectively eliminates the preferred orientation caused by texture formation during plastic deformation. Taking into account, these two aspects provide the theoretical frame for phase quantification using pole figure measurements and texture data analysis.

Therefore, the volume fraction ratio of the two phases austenite and ferrite in ADI can be expressed as the ratio of their scattering intensities using Eq. (4).

$\frac{I_{\gamma},(111)}{I_{\alpha},(110)}=\frac{\mathrm{KV}_{\gamma} R_{\gamma},(111) A_{m}}{\mathrm{KV}_{\alpha} R_{\alpha},(110) A_{m}}=\frac{V_{\gamma} R_{\gamma},(111)}{V_{\alpha} R_{\alpha},(110)}$

Equation (4) can also be used to calculate and compare the same phase (austenite) fractions in different deformed ADI samples. In the subsequent calculation of the martensite content, Eq. (4) can be converted to Eq. (5). Nevertheless, two basic requirements are necessary for successful application of this calculation. First, the phase should have at least one independent reflection in the diffraction pattern without any peak overlap. Second, among a group of samples, the known phase composition of an initial sample is needed as a reference.

$\frac{V_{\gamma}^{\varepsilon}}{V_{\gamma}^{0}}=\frac{I_{\gamma, \mathrm{hkl}}^{\varepsilon}}{I_{\gamma, \mathrm{hkl}}^{0}}$, Martensite phase fraction $=V_{\gamma}^{0}-V_{\gamma}^{\varepsilon}$

$V_{\gamma}^{\varepsilon}$ : Volume fraction of austenite at strain level $\varepsilon, V_{\gamma}^{0}$ : initial volume fraction of austenite at $0 \%$ strain, $I_{\gamma, h k l}^{\varepsilon}$ : 
integrated intensity of reflection $(h k l)$ of austenite in ADI at strain level $\varepsilon$ and $I_{\gamma, h k l}^{0}$ : initial integrated intensity of reflection $(h k l)$ of austenite in ADI at $0 \%$ strain.

Taking the neutron diffraction pattern in Fig. 7 as an example: Due to peak overlap of austenite (111), ferrite (110) and martensite (101), (110) reflections around $2 \theta=44^{\circ}$ and ferrite (200), martensite (200) around $2 \theta=66^{\circ}$, only the austenite (200) peaks fulfil the basic requirements and its pole figure can be used for further quantitative phase analysis. The experimental conditions of the texture measurement have to be set identical for all measured ADI samples. In such experimental conditions/settings, the peak intensity of austenite (200) in different ADI samples can be compared directly without further normalization. The samples used in this experiment were ADI with $0 \% \mathrm{Ni}$ austempered at $350{ }^{\circ} \mathrm{C}$ and plastic deformed from strain level $0 \%$ to $45 \%$ in $5 \%$ increments (10 samples). Texture analysis was performed on five of these ten samples which plastic deformed to $0 \%, 10 \%, 20 \%, 30 \%$ and $40 \%$ strain levels. As the initial austenite phase fraction in ADI without plastic deformation has already been calculated using Eq. (4), the austenite fraction of the other plastic deformed ADI samples can be obtained straightforward using Eq. (5). The austenite content difference between the deformed samples and the reference sample is directly proportional to the martensite phase fraction, and the results are depicted in Fig. 8 for comparison with the results obtained from the Rietveld method [20].

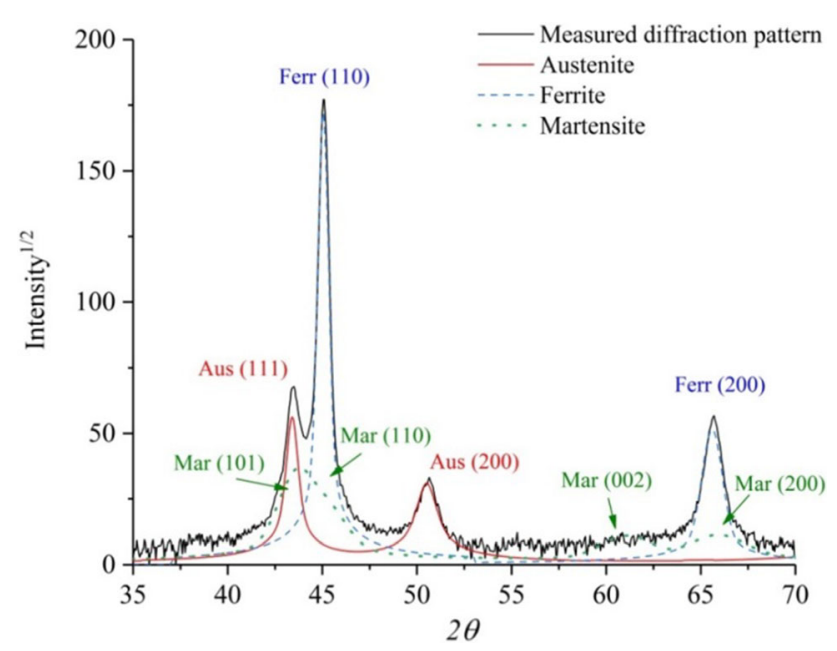

Figure 7 Neutron diffraction pattern of ADI austempered at $350{ }^{\circ} \mathrm{C}$ and compressed to $35 \%$ strain level as an example.
The crystal structure type of martensite chosen for Rietveld refinement is bct martensite, the lattice parameter in this bct crystal structure model is based on our previous TEM investigation on the martensite in ADI [20]. Small amount of hcp martensite may also exist at strong plastic deformation (the slight inflection at $2 \theta \approx 55^{\circ}$ shown in Fig. 7 may be due to $h c p$ martensite). Since no evidence of its existence was found in the high-resolution neutron diffraction pattern and TEM results, it was not.

taken into account in the phase quantification using the Rietveld method.

The previous results in quantitative phase analysis using different diffraction techniques have already shown that the minimum error of quantitative phase calculation, i.e., accuracy, from standard Rietveld analysis in different materials is about 1 to 3 vol. \%, depending on the diffraction technique, the instruments used and materials properties [9-13]. Comparison of the results obtained from the texture analysis and the values from the reference Rietveld method in Fig. 8 shows that the difference in determined martensite content is less than 2.5 vol. \%, which is well within the error range of standard Rietveld analysis. This illustrates the high precision and good practicability of texture data analysis in phase quantification. Further, this method has quite a few advantages when compared to full powder diffraction measurements and subsequent standard Rietveld analysis. The data analysis process of this method is much simpler. Only the integrated intensity of one single peak needs to be analyzed. In

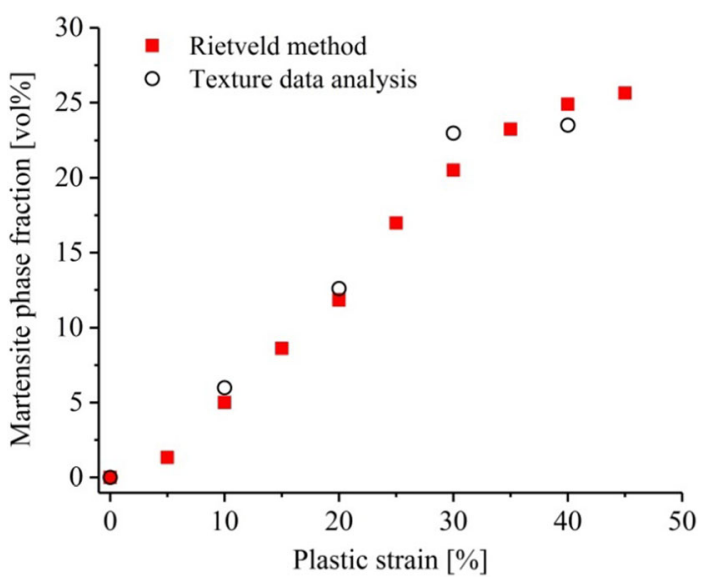

Figure 8 Comparison of Rietveld method and texture data analysis in martensite phase quantification. The ADI samples with $0 \mathrm{wt} \% \mathrm{Ni}$ content and austempered at $350{ }^{\circ} \mathrm{C}$ were compressed to different strain levels between 0 and $45 \%$. 
addition, the microstructural effects, i.e., grain size, microscopic strain, texture etc., which might complicate the Rietveld analysis can be avoided. In consequence, the necessary long-term data analysis experience using Rietveld refinement software is not required making the texture method suitable also for non-expert users of diffraction. This is a significant advancement in methodology for using the diffraction method for phase quantification. Finally, by virtue the method to analyze single pole figures avoids the influence of strong texture formation on phase calculation effectively. In the Rietveld refinement approach with inclusion of texture, either errors in ODF calculation or uneven spatial distribution of texture in the samples will affect the phase calculation considerably.

\section{Conclusion}

The following conclusion can be drawn after comparing the scope of quantitative phase analysis using different neutron diffraction and imaging methods:

1. Standard Rietveld refinement with consideration on texture formation is a comprehensive and wellproven analysis method for phase quantification in all sorts of materials. Usually no reference samples are needed with this methodology. However, the measurement and especially the data analysis process are relatively complex and time consuming. In general, the neutron diffraction beam time limits the number of samples.

2. BET offers the possibility to measure several samples within one measurement. It can provide additionally three-dimensional quantitative phase content information that the other methods cannot. The data analysis process using BET is not as complicated as the standard Rietveld refinement, but several reference samples with known phase composition are needed for calculation correction factors; therefore, it has to be combined with other methods for phase analysis.

3. Phase quantification using texture/pole figure data has the simplest data analysis process within these methods. It can provide accurate results and avoids a series of problems in diffraction-based quantitative phase analysis like peak overlap and texture formation. It is an effective method in phase quantification for following the phase content of a particular phase through phase transformations, i.e., martensite development in iron alloys after plastic deformation. However, it also needs at least one reference sample with a known initial composition.

\section{Acknowledgements}

Funding by Grant PE 580/14-1 (Project: 233737539) and PE 580/16-1 (Project: 28975656) of the Deutsche Forschungsgemeinschaft (DFG) is gratefully acknowledged.

\section{Funding}

Open Access funding enabled and organized by Projekt DEAL.

\section{Compliance with ethical standards}

Conflict of interest The authors have no conflict of interest.

Open Access This article is licensed under a Creative Commons Attribution 4.0 International License, which permits use, sharing, adaptation, distribution and reproduction in any medium or format, as long as you give appropriate credit to the original author(s) and the source, provide a link to the Creative Commons licence, and indicate if changes were made. The images or other third party material in this article are included in the article's Creative Commons licence, unless indicated otherwise in a credit line to the material. If material is not included in the article's Creative Commons licence and your intended use is not permitted by statutory regulation or exceeds the permitted use, you will need to obtain permission directly from the copyright holder. To view a copy of this licence, visit http://creativecommons.org/licen ses $/$ by $/ 4.0 /$.

\section{References}

[1] Khokhar FS (2005) Quantitative analysis of multi-phase system steels with mixture of ferrite and austenite. $\mathrm{PhD}$ Dissertation, Linköping University

[2] Morawiec M, Grajcar A (2017) Some aspects of the determination of retained austenite using the Rietveld refinement. 
JAMME 80:11-17. https://doi.org/10.5604/01.3001.0010. 1442

[3] Varbai B, Pickle T, Májlinger K (2018) Development and comparison of quantitative phase analysis for duplex stainless steel weld. Period Polytech Mech Eng 62(3):247-253. h ttps://doi.org/10.3311/PPme.12234

[4] Zrník J, Muránsky O, Lukás P, Nový Z, Sittner P, Horňak P (2006) Retained austenite stability investigation in TRIP steel using neutron diffraction. Mater Sci Eng A 437:114-119. https://doi.org/10.1016/j.msea.2006.04.067

[5] Júnior AF, Otubo J, Magnabosco R (2016) Ferrite quantification methodologies for duplex stainless steel. J Aerosp Technol Manag 8(3):357-362. https://doi.org/10.5028/jatm. v8i3.653

[6] Korcakova L, Hald J, Somers MAJ (2001) Quantification of laves phase particle size in $9 \mathrm{CrW}$ steel. Mater Chara 47:111-117. https://doi.org/10.1016/S1044-5803(01)001590

[7] Schofield PF, Knight KS, Covey-crump SJ, Cressey G, Stretton IC (2002) Accurate quantification of the modal mineralogy of rocks when image analysis is difficult. Mineral Mag 66(1):189-200. https://doi.org/10.1180/ 0026461026610022

[8] Anders Säfsten (2009) Quantitative phase analysis of duplex stainless steels as a function of heat treatment. Master thesis, Luleå University of Technology. 2009: 129 CIV-ISSN: 1402-1617-ISRN: LTU-EX-09/129-SE

[9] De la Torre AG, Aranda MAG (2003) Accuracy in Rietveld quantitative phase analysis of Portland cements. J Appl Cryst 36:1169-1176. https://doi.org/10.1107/ S002188980301375X

[10] Bish DL, Post JE (1993) Quantitative mineralogical analysis using the Rietveld full-pattern fitting method. Am Mineral 78(9-10):932-940

[11] Hill RJ, Howard CJ (1987) Quantitative phase analysis from neutron powder diffraction data using the Rietveld method. J Appl Cryst 20:467-474. https://doi.org/10.1107/ S0021889887086199

[12] Bish DL, Howard SA (1988) Quantitative phase analysis using the Rietveld method. J Appl Cryst 21:86-91. https://d oi.org/10.1107/S0021889887009415

[13] Järvinen M (1993) Application of symmetrized harmonics expansion to correction of the preferred orientation effect. J Appl Cryst 26:525-531. https://doi.org/10.1107/ S0021889893001219

[14] Ferrari M, Lutterotti L (1994) Method for the simultaneous determination of anisotropic residual stresses and texture by X-ray diffraction. J Appl Phys 76(11):7246-7255. https://d oi.org/10.1063/1.358006
[15] Priesmeyer HG (1988) Neutron strain radiography. In: international conference on residual stresses ICRS 2: 197. ISBN 978-94-009-1143-7

[16] Bowman CD et al. (1989) Analysis of materials under transient conditions using single pulses from LANSCE. Los Alamos National Laboratory Report LA-11875-PR, p.42

[17] Meggers K, Priesmeyer HG, Trela WJ, Bowman CD, Dahms M (1994) Real time neutron transmission investigation of the austenite-bainite transformation in grey iron. NIM B 88:423-429. https://doi.org/10.1016/0168-583X(94)95394-5

[18] Woracek R, Santisteban J, Fedrigo A, Strobl M (2018) Diffraction in neutron imaging - a review. Nucl Instrum Methods Phy Res A 878:141-158. https://doi.org/10.1016/j. nima.2017.07.040

[19] Brokmeier H-G (1991) Quantitative phase analysis of textured materials. Mater Sci Forum 79-82:67-72. https://doi. org/10.4028/www.scientific.net/MSF.79-82.67

[20] Li XH, Saal P, Gan WM, Hoelzel M, Volk W, Petry W, Hofmann M (2018) Strain-induced martensitic transformation kinetic in austempered ductile iron (ADI). Metall Mater Trans A 49A:94-104. https://doi.org/10.1007/s11661-017-4 420-3

[21] Saal P, Meier L, Li XH, Hofmann M, Hoelzel M, Wagner JN, Volk W (2016) In situ study of the influence of nickel on the phase transformation kinetics in austempered ductile iron. Metall Mater Trans A 47:661-671. https://doi.org/10. 1007/s11661-015-3261-1

[22] Hoelzel M, Gan WM, Hofmann M, Randau C, Seidl G, Juettner P, Schmahl WW (2013) Rotatable multifunctional load frames for neutron diffractometers at FRM II-design, specifications and applications. Nucl Instr Methods Phys Res A 711:101-105. https://doi.org/10.1016/j.nima.2013.01.049

[23] Hoelzel M, Senyshyn A, Juenke N, Boysen H, Schmahl W, Fuess H (2012) High-resolution neutron powder diffractometer SPODI at research reactor FRM II. Nucl Instrum Methods Phys Res A 667:32-37. https://doi.org/10.1016/j. nima.2011.11.070

[24] Hofmann M, Gan WM, Rebelo-Kornmeier J (2015) STRESS-SPEC: materials science diffractometer. J Large Scale Res Facil 1:A6. https://doi.org/10.17815/jlsrf-1-25

[25] Maier-Leibnitz HZ et al (2015) ANTARES: cold neutron radiography and tomography facility. J Large Scale Res Facil 1:17. https://doi.org/10.17815/jlsrf-1-42

[26] Calzada E, Gruenauer F, Mühlbauer M, Schillinger B, Schulz M (2009) New design for the ANTARES-II facility for neutron imaging at FRM II. Nucl Instrum Methods Phys Res Sec A Accel Spectrom Detect Assoc Equip 605(1-2):50-53. https://doi.org/10.1016/j.nima.2009.01.192

[27] Schulz M, Böni P, Calzada E, Mühlbauer S (2009) Energydependent neutron imaging with a double crystal 
monochromator at the ANTARES facility at FRM II. Nucl Instrum Methods Phy Res A 605:33-35. https://doi.org/10. 1016/j.nima.2009.01.123

[28] Kropff F, Granada JR, Mayer RE (1982) The bragg lineshapes in time-of-flight neutron powder spectroscopy. Nucl Instrum Methods Phy Res 198:515-521. https://doi.org/10. 1016/0167-5087(82)90293-9

[29] Boin M (2012) nxs: a program library for neutron cross section calculations. J Appl Cryst 45:603-607. https://doi. org/10.1107/S0021889812016056

[30] Steuwer A, Withers PJ, Santisteban JR, Edwards L (2005) Using pulsed neutron transmission for crystalline phase imaging and analysis. J Appl Phy 97:074903. https://doi.org/ 10.1063/1.1861144

[31] Bourke MAM, Maldonado JG, Masters D, Meggers K, Priesmeyer HG (1996) Real time measurement by Bragg edge diffraction of the reverse $\left(\alpha^{\prime} \rightarrow \gamma\right)$ transformation in a deformed 304 stainless steel. Mater Sci Eng A 221:1-10. h ttps://doi.org/10.1016/S0921-5093(96)10378-6

[32] Verbeken K, Van Caenegem N, Raabe D (2009) Identification of e martensite in a Fe-based shape memory alloy by means of EBSD. Micron 40:151-156. https://doi.org/10.10 16/j.micron.2007.12.012

[33] Beese AM Mohr D (2009) Experimental quantification of phase transformation in austenitic stainless steel.In: proceedings of the SEM annual conference 2: 1094-1100. ISBN-9781615671892
[34] Kardjilov N, Hilger A, Manke I, Woracek R, Banhart J (2016) CONRAD-2: the new neutron imaging instrument at the Helmholtz-Zentrum Berlin. J Appl Cryst 49:195-202. h ttps://doi.org/10.1107/S1600576715023353

[35] Soria SR, Li XH, Schulz M, Boin M, Hofmann M (2020) Determination of martensite content and mapping phase distribution on austempered ductile iron using energy-selective neutron imaging. Mater Charact 166:110453. http s://doi.org/10.1016/j.matchar.2020.110453

[36] Salvemini F, Grazzi F, Peetermans S, Civita F, Franci R, Hartmann S, Lehmann E, Zoppia M (2012) Quantitative characterization of Japanese ancient swords through energyresolved neutron imaging. $J$ Anal At Spectrom 27:1494-1501. https://doi.org/10.1039/c2ja30035d

[37] Meier L (2015) In-situ-Messung der Phasenumwandlungskinetik von aus-ferritischem Gusseisen. PhD Dissertation, TU Munich

[38] Spieß L et al (2019) Moderne Röntgenbeugung 3. Aufl. Springer Spektrum (C) Springer Fachmedien Wiesbaden GmbH, pp. 259-274. https://doi.org/10.1007/978-3-8348-8 232-5

Publisher's Note Springer Nature remains neutral with regard to jurisdictional claims in published maps and institutional affiliations. 